
IP Periodica Polytechnica
Civil Engineering

61 (4), pp. 958-971, 2017

https://doi.org/10.3311/PPci.9346

Creative Commons Attribution (i)

RESEARCH ARTICLE

\section{Numerical Modelling of a Novel Joint System for Grid Shells with T Cross- sections}

\author{
Kitti Gidófalvy ${ }^{1 *}$, Huihuan $\mathrm{Ma}^{2}$, Levente T. Katula ${ }^{1}$
}

Received 18 April 2016; Accepted 04 July 2016

\begin{abstract}
A novel joint system developed for single-layered steel grid shells with T cross-sections is presented in this paper. The joint system is bolted to facilitate quick and easy on-site assembly.

First, a solid finite element model was built to investigate the behaviour of the developed joint system. The moment-rotation characteristics of the joint system were determined and the joint strength and stiffness was investigated. Key parameters influencing the behaviour of the joint were studied, such as bolt diameter, pretension, component geometry and normal force.

As a second step, free-form roof structures with a span of $40 \div 80$ meters were chosen and analysed with the developed joints. The previously obtained moment-rotation results were used as spring moment-rotation characteristics in beam finite element models. The load bearing capacity of the structures were determined. The results were compared to that of grid shells with rigid joints, and it was shown that the joint system is stiff enough.
\end{abstract}

\section{Keywords}

steel joint, reticulated shell, grid shell, solid finite element model, semi-rigid joint, T cross-section

\footnotetext{
${ }^{1}$ Budapest University of Technology and Economics, Hungary

Department of Structural Engineering

${ }^{2}$ Harbin Institute of Technology, China

Space Structures Research Center, School of Civil Engineering

*Corresponding author email: gidofalvy.kitti@epito.bme.hu
}

\section{Introduction}

Single-layered steel grid or reticulated shells are recently designed with complex geometry: the mid-surface of the shell is irregular and doubly-curved, thus the name free-form. This paper deals with roof structures with rectangular boundary (Fig. 1). While the structural behaviour of simpler regular geometrical shapes - such as domes, barrel vaults, elliptic translational surfaces, etc. - are regularly studied, free-form structures are rarely researched.

Single-layer grid shell structures are usually designed using pipe cross-section. Lately, rectangular cross-sections are more often used, while its out-of-plane inertia could be increased, which is a must for free-form or larger span shells. This paper investigates welded T cross-sections, which is a cheaper alternative for the rectangular cross-section.

Double-layer steel shells are generally built with simple bolted joints that are considered as pinned connections in design. However, a single-layered grid shell, if designed with pinned connections, it requires a shape with high curvature thus the structural height needs to be increased. If the shape is shallow, the connections need to be rigid. Rigid connections are usually realized by welding.

Using bolted joints in single-layer steel grid shells is advantageous. Compared to welding, assembly is less laborious and on-site assembly demands less expertise, thus the structure may become more economic. Bolted joints usually have lower rigidity than welded ones. They are referred to as semi-rigid or semi-continuous joints, emphasising that the stiffness of joints have a significant effect on the structures they are used in. Use of semi-rigid joints for grid-shells is a new area in design and research. For free-form structures, joints need to meet not only stiffness but also geometric requirements: it must be possible to easily adjust the joints to the varying geometrical parameters. New joint systems are being developed which are easy to assemble, and economic. Such joints were collected and summarized by Stephan et al. in [1].

Numerical and experimental analysis of frame joints are regularly studied, while there are a lot less research focusing on joints for grid shells $[2,3,4,5,6]$. Ma et al. [2,3] studied a 

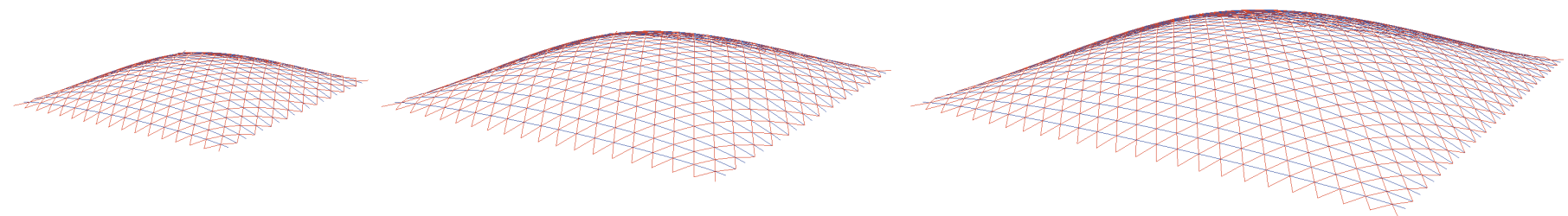

Fig. 1 The analysed grid shell structures with square boundary with 40, 60 and 80 meters span

bolt-ball (similar to the MERO system) and a socket joint. Both have only one bolt parallel to the pipe beam, thus the bending stiffness is low. Such joints are called end-face joints [1], in which the bolts are in tension. Lopez et al. [4] analysed a similar joint system called ORTZ. Both research teams performed numerical and experimental analyses of these joints. They applied the obtained moment-rotation results for domes with a span of $20 \div 60$ meters and for small span $(30 \div 40 \mathrm{~m})$ free-form structures.

For larger span structures and for grid shells with a more complex shape, stiffer joints are needed. Hwang et al. [5] performed numerical analysis on four different bolted grid shell joints, all of them used in structures built recently. These joints are either end-face joints with two bolts one above the other or splice joints with one or two bolts. Splice joints use bolts perpendicular to the shell surface [1], thus bolts are mainly in shear. The analysed joints by Hwang et al. connect beams of rectangular cross-section of the same section size. From their research, it can be seen, that the end-face joint is stiffer and has a higher out-of-plane moment capacity.

Thus, using not only one, but two bolts in an end-face joint, the out-of-plane bending rigidity may be significantly increased. For single-layer grid shells, the out-of-plane stiffness needs to be higher than the in-plane stiffness. Rectangular hollow cross-sections with larger height are thus regularly applied for free-form shells. Similarly, T sections may be applied as for example in the free-form roof in the New Milan Trade Fair in Italy.

In this paper, a new joint system is developed and studied, in which $4 \div 6$ beams with $\mathrm{T}$ cross-sections are joined together and that may be used for free-form structures with a medium or large span $(>40 \mathrm{~m})$. The goal is to determine the momentrotation capacity of the joint and to demonstrate their applicability in free-form steel grid shell structures with various span.

\section{Methodology}

In order to study the behaviour of the new joint system, a solid finite element model was built. A parameter study was performed to understand the behaviour of the joint and to reveal the main components influencing its behaviour. As a results of this study, moment-rotation characteristics of the joint were obtained. They were directly used in the analysis of grid shell structures.
The developed joint system may be used for single-layer free-form grid shells of various spans. To demonstrate that the joints are effective, free-form triangular grid shells with a square boundary (Fig. 1) were designed with this joint system. The generation and details of this free-form shape is described in [7]. The load bearing capacity or the ultimate load $\left(q_{\max }\right)$ of these structures were determined based on materially and geometrically nonlinear finite element analysis excluding the effect of imperfections (GMNA). Calculating local stability failures (flexural-, torsional- and lateral torsional buckling) is beyond the scope of this paper.

The designed grid shells are shallow, as the span-to-height ratio is 8 . To show that the designed joints are effective, the ultimate load of these structures with the developed bolted joints (semi-rigid structures, $q_{\max , \mathrm{sr}}$ ) and with rigid joints (rigid structures, $q_{\text {max, }}$ ) are compared. A semi-rigid joint is effective and economic if the ultimate load of the rigid structure and the semi-rigid structure with the bolted joint is similar. This can be calculated by the ratio of $\lambda=q_{\max , \mathrm{sr}} / q_{\max , \mathrm{r}}$. In this paper, as a definition, a joint is effective if $\lambda$ is minimum 0.8 .

Two types of $\mathrm{T}$ joints are designed as it will be detailed in the next section. For each type, cross-section sizes are chosen that can be used for the roof structures with a span of 40,60 and 80 meters. Table 1 shows the cross-section dimensions and properties of the altogether six cross-sections. Table 2 shows the geometrical parameters of the related roof structures. The buckling reduction factors $(\chi)$ are calculated according to the Eurocode [8] with the assumption that the buckling length is the maximum beam length in the structure $\left(L_{\max }\right)$. Boundary nodes are all pinned. The ultimate load is calculated under uniform dead load transferred to and acting on the nodes. As it can be seen in this table, the load bearing capacities are all higher or close to $8 \mathrm{kN} / \mathrm{m}^{2}$. This value is high enough for roof structures with glass cladding designed for wind and snow load in Hungary.

The ultimate load of structures with a joint that is pinned about the weak axis but rigid about the strong axis $\left(q_{\text {max, }}\right)$, were also calculated (Table 2). Compared to $q_{\text {max,r }}$, these are about $80 \%$ lower. This shows, that the in-plane rigidity of the joint can not be simplified as pinned, when determining the ultimate load of structures. 
Table 1 Cross-section dimensions and resistances

\begin{tabular}{|c|c|c|c|c|c|c|c|}
\hline Name of section/joint & $b[\mathrm{~mm}]$ & $t_{\mathrm{f}}[\mathrm{mm}]$ & $h[\mathrm{~mm}]$ & $t_{\mathrm{w}}[\mathrm{mm}]$ & $A\left[\mathrm{~mm}^{2}\right]$ & $I_{\mathrm{y}}\left[\mathrm{cm}^{4}\right]$ & $I_{\mathrm{z}}\left[\mathrm{cm}^{4}\right]$ \\
\hline A40 & 60 & 40 & 160 & 14 & 4080 & 866 & 75 \\
\hline A60 & 80 & 40 & 200 & 14 & 5440 & 1838 & 174 \\
\hline A 80 & 100 & 40 & 240 & 16 & 7200 & 3680 & 340 \\
\hline B40 & 100 & 20 & 140 & 14 & 3680 & 656 & 169 \\
\hline B60 & 120 & 20 & 200 & 14 & 4920 & 1918 & 292 \\
\hline B80 & 140 & 20 & 240 & 18 & 6760 & 3968 & 468 \\
\hline
\end{tabular}

Table 2 Geometrical properties of the roof structures and their ultimate load with rigid joints

\begin{tabular}{|c|c|c|c|c|c|c|c|c|c|}
\hline \multirow{2}{*}{ Name of joint } & \multirow{2}{*}{ Span $[\mathrm{m}]$} & \multirow{2}{*}{$\begin{array}{c}\text { Span to high } \\
\text { ratio }\end{array}$} & \multicolumn{2}{|c|}{ No. of along } & \multirow{2}{*}{$\begin{array}{c}q_{\max , \mathrm{r}} \\
{\left[\mathrm{kN} / \mathrm{m}^{2}\right]}\end{array}$} & \multirow{2}{*}{$\begin{array}{c}q_{\max , \mathrm{p}} \\
{\left[\mathrm{kN} / \mathrm{m}^{2}\right]}\end{array}$} & \multirow{2}{*}{$L_{\max }[\mathrm{m}]$} & \multirow{2}{*}{$\chi_{y}[-]$} & \multirow{2}{*}{$\chi_{z}[-]$} \\
\hline & & & $\mathrm{x}$ dir. & y dir. & & & & & \\
\hline A 40 & 40 & 8 & 16 & 20 & 12.3 & 2.8 & 2.8 & 0.76 & 0.17 \\
\hline A60 & 60 & 8 & 19 & 24 & 8.6 & 1.5 & 3.6 & 0.75 & 0.17 \\
\hline A 80 & 80 & 8 & 24 & 34 & 7.8 & 1.0 & 3.7 & 0.81 & 0.23 \\
\hline B40 & 40 & 8 & 16 & 20 & 12.1 & 3.0 & 2.8 & 0.72 & 0.35 \\
\hline B 60 & 60 & 8 & 19 & 24 & 8.2 & 1.5 & 3.6 & 0.78 & 0.29 \\
\hline B80 & 80 & 8 & 24 & 34 & 7.9 & 1.0 & 3.7 & 0.83 & 0.32 \\
\hline
\end{tabular}
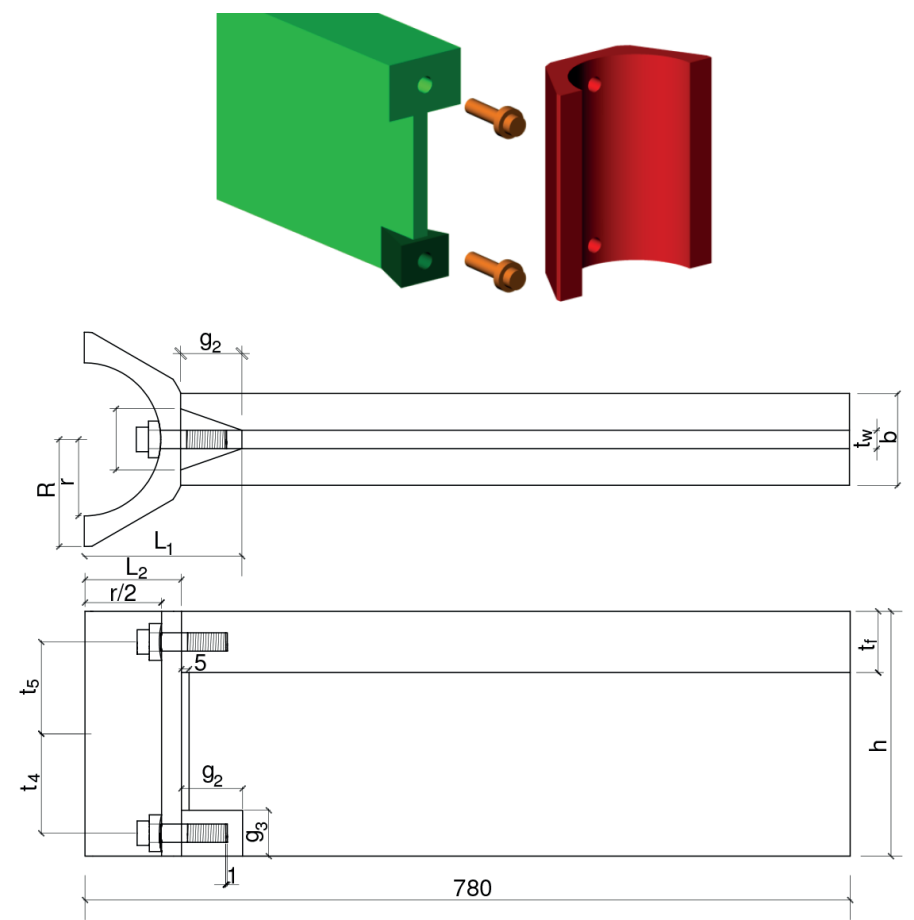

Fig. 2 Joint System A - thick, narrow flanges; one bolt in flange and one in welded end-element

\section{The developed $\mathrm{T}$ joint system}

\subsection{Geometrical details of the analysed joints}

In this section, the details of the joint system are presented. The joint consists of a cylindrical nodal element (red in Fig. 2-3), to which the T beam members (light green in Fig. 2-3) are bolted with the help of end-elements (dark green in Fig. 2-3). The thick trapezoidal end-elements are welded to the beam ends. The joint system is an end-face joint [1], where the axes of the two bolts are parallel with the beam axis, thus they are mainly under axial load.

Two slightly different versions have been designed, namely System A and B. System A (Fig. 2) has a thick ( $t_{\mathrm{f}}=40 \mathrm{~mm}$ ), narrow flange to which the upper bolt is connected. The lower bolt is connected to a short end-element. In System B (Fig. 3), the flanges are thin $\left(t_{\mathrm{f}}=20 \mathrm{~mm}\right)$ and wide, and both bolts are connected to a larger end-element. The cross-section sizes of System A and B (Table 1), denoted with the same number, were determined so as to have the same web height, similar out-of-plane inertia and sufficient in-plane inertia (Table $1 I_{\mathrm{y}}$ and $I_{\mathrm{z}}$ respectively). This latter criteria was more difficult to meet for System A, thus, the crosssection area is slightly larger for System A than for B.

Due to its narrower flange, System A requires smaller nodal elements, and is more aesthetic, while System B has higher in-plane inertia $\left(I_{\mathrm{z}}\right)$. The nodal element is designed to be rigid compared to the rest of the joint and the member, so they exhibit a negligible deformation. High strength bolts (M12 or M16, 10.9) are used (Fig. 4). 

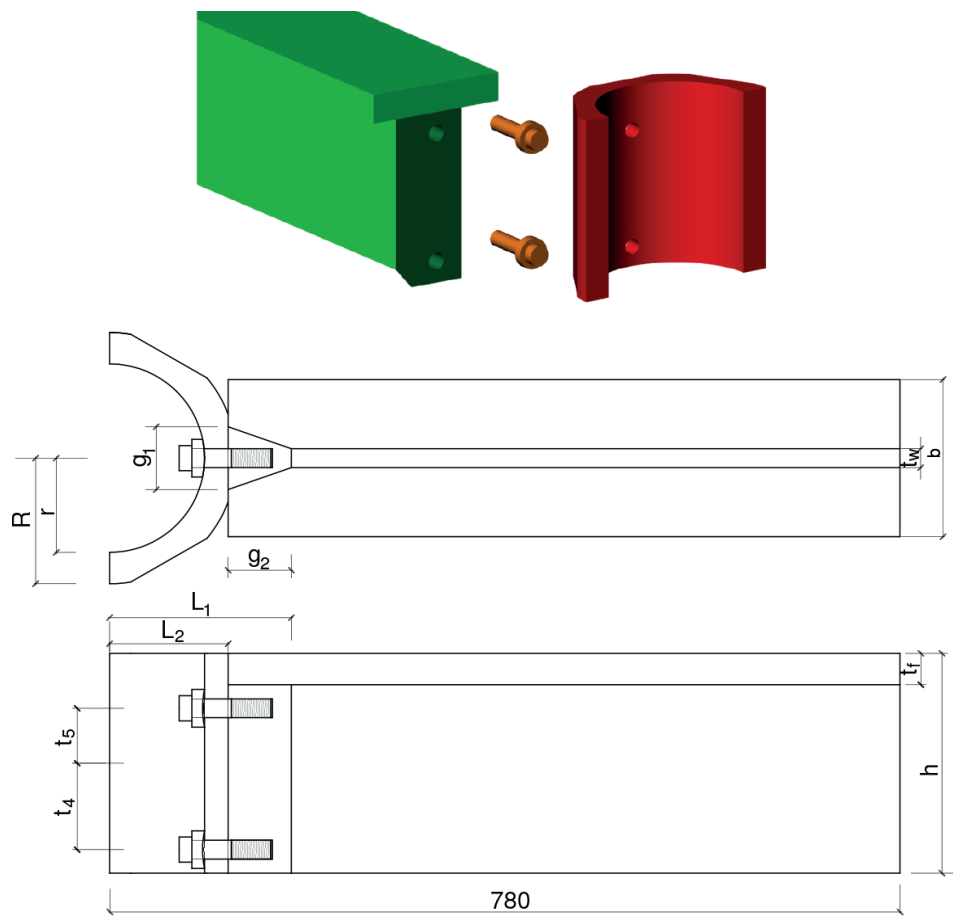

Fig. 3 Joint System B - thin, wide flanges; bolts in welded end-element

Table 3 Geometric details of the analysed joints

\begin{tabular}{|c|c|c|c|c|c|c|c|c|c|c|c|c|c|c|c|c|c|c|c|c|}
\hline Name of joint & $b$ & $t_{\mathrm{f}}$ & $t_{\mathrm{w}}$ & $h$ & $r$ & $R$ & $L_{1}$ & $L_{2}$ & $d_{1}$ & $\begin{array}{c}d_{2} \\
\end{array}$ & $t_{1}$ & $b_{2}$ & $b_{1}$ & $d_{3}$ & $t_{2}$ & $t_{4}$ & $t_{5}$ & $g_{1}$ & $g_{2}$ & $g_{3}$ \\
\hline A40 & 60 & 40 & 14 & 160 & 50 & 70 & 103 & 63 & 12 & 22 & 8 & 45 & 23 & 24 & 6 & 100 & 25 & 60 & 40 & 40 \\
\hline B40 & 100 & 20 & 14 & 140 & 60 & 80 & 115 & 75 & 12 & 22 & 8 & 45 & 23 & 24 & 6 & 55 & 35 & 55 & 40 & - \\
\hline
\end{tabular}

As already discussed, free-form grid shell joints are required not only to be able to transfer high out-of-plane bending moments, but there are requirements for the geometry and assembly as well. As each joint is different in a free-form shell, it is preferable that the joint has least custom fabricated parts. In this joint, the nodal element is cut from a cylinder, with a different plane for each connected beam. The assembly and geometry of this joint is flexible enough to allow it to be adjusted to the applied free-form shell. The joint may easily be adopted to horizontal angles [1] because of the slender cross-sections and the cylindrical nodal element. It can be adopted to vertical angles in a wide range by cutting the end of the $\mathrm{T}$ section web. It may also be adjusted to small twist angles. For simplicity, in this paper, only joints with zero vertical and twist angles are analysed.

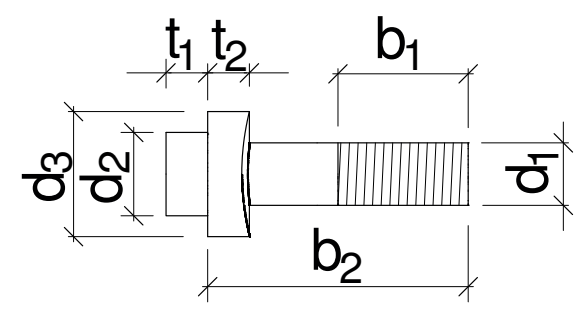

Fig. 4 Bolt with washer

\subsection{Solid finite element model}

A solid finite element model is built in Ansys 14.5 [9] to study the moment-rotation behaviour of the joint. A cantilever with one beam element and a half of a nodal element is modelled to determine the bending behaviour of the joint (Fig. 5). All nodes are fixed at the end surfaces of the nodal element. To introduce a moment about the weak (in-plane, $z$ ) and strong (out-of-plane, $y$ ) axes, a point load $\mathrm{F}$ is applied at the end of the cantilever beam. The bending moments (M) are calculated at the end of the beam element according to Fig. 6 and Eq. (1-2).

A 10-node tetrahedral solid finite element is used (SOLID187) that has a quadratic displacement behaviour. This element is suitable for meshing volumes imported from CAD programs. A sufficiently fine mesh density is applied. The geometry is defined in the CAD software Rhinoceros [10] with Grasshopper [11].

$$
\begin{gathered}
M=F \cdot L_{n} \cdot \cos (\phi) \\
\phi=\arctan \left(\Delta / L_{n}\right)
\end{gathered}
$$




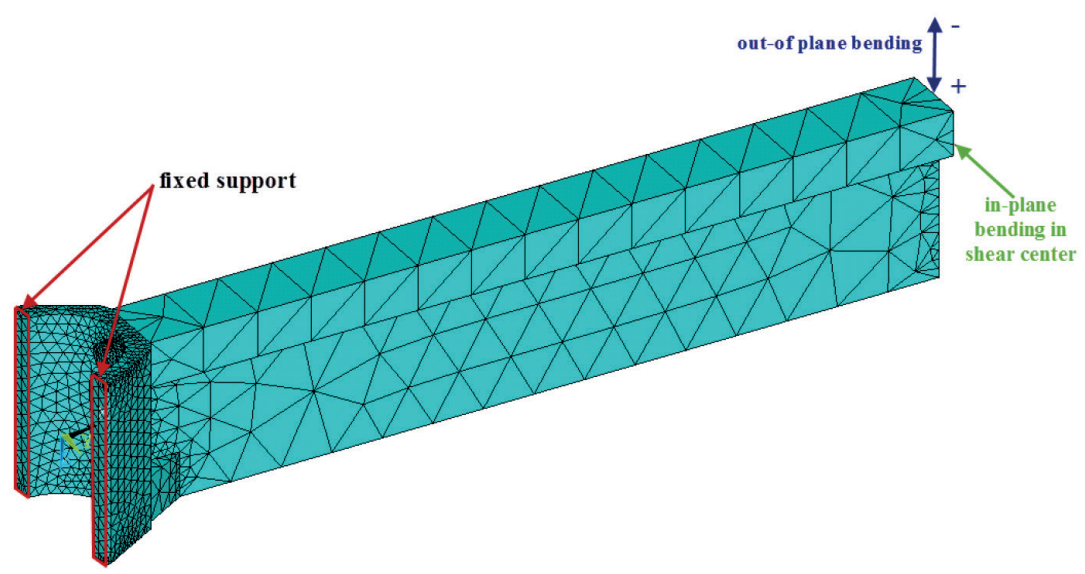

Fig. 5 Modelling a cantilever with one beam and half of the nodal element

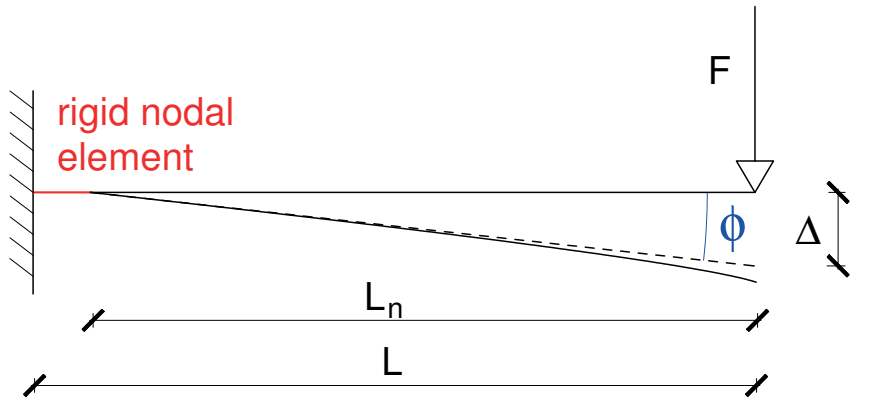

Fig. 6 Loading and definition of the rotation $(\phi)$

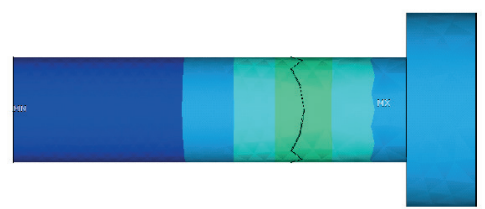

Fig. 7 Bolt deformations after pretension; contour of the pretension section can be seen as a black curve

\subsubsection{Pretension}

Pretension in the bolt is modelled using the PRETS179 elements with one translational degree of freedom. A so-called pretension section is defined in the bolt with a set of pretension elements. In the first load step, a pretension force is applied on these elements. The effect of this force is then preserved as a displacement in the next load step, when bending is applied on the beam. The pretension section is located along the bolt, in between the end-element (or flange) and the nodal element (Fig. 7).

\subsubsection{Contact surfaces}

Throughout the loading of the joint, surfaces of the components of the joints may come into or lose contact with each other. Such phenomena are modelled with the help of contact (CONTA174) and target (TARGE170) shell finite elements that are generated on the surface of solid elements that may come into contact. Target elements are rigid elements that may penetrate into flexible contact elements. Apart from the stiffness of the contact, friction can also be modelled with this element.

Contact and target surfaces are generated between the following components of the model (Fig. 8):

- nodal element - washers: C1, C2

- nodal element - bolts: C3, C4

- nodal element - beam: C5

- nodal element - end-element: C6

- bolts - flange or end-element: C7, C8

Designation of contact and target surfaces may be of high importance. Generally speaking, the stiffer components (higher $f_{y}$ or larger thickness, Table 4) are chosen to be the target elements. As for the surfaces between the node and the beam or endelement, it is not obvious which is stiffer. This problem is analysed by defining both surfaces as contact and target elements at the same time. The results show little difference from the finally applied designation. Contact stiffness parameters are automatically determined by the program. The coefficient of friction for the contact surface is assumed as 0.44 [12], but has little effect on the moment-rotation characteristics of the joint.
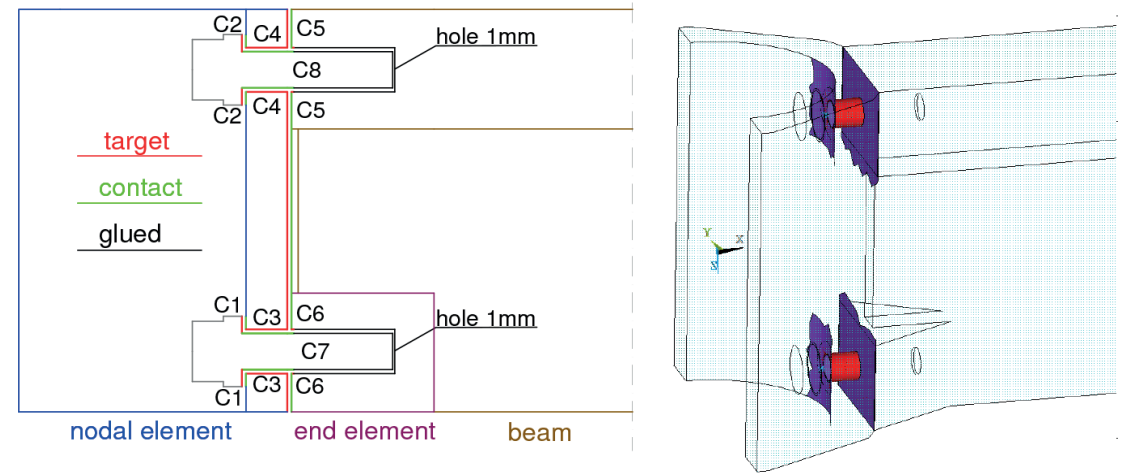

Fig. 8 Contact and target surfaces in joint System A 
Fig. 8 also shows surfaces that are modelled to fully work together by gluing them in the finite element model, such as the surfaces that are welded to each other. The threaded part of the bolt is glued to the beam flange and to the end-elements, while there is a hole of $1 \mathrm{~mm}$ at the end of the bolt.

The contact surfaces (C3-4) between the nodal element and bolts are initially open, as the bolt hole is slightly bigger than the diameter of the bolt. For simplicity, the washers and bolts are also glued to each other, while they have small effect on the overall results [5]. The bolt head is modelled as a cylinder, for simplicity.

\subsubsection{Material properties}

The applied material properties are based on the Eurocode $[13,14]$, hence the elastic modulus is $210 \mathrm{kN} / \mathrm{mm}^{2}$, and the Poisson's ratio is 0.3 . Bilinear elastic, perfectly-plastic stress-strain characteristics are applied for all joint components, except for the bolt. The beam and the end-elements are made of S235, while the node and washer are made of S355.

As the expected failure of the joint is bolt fracture, the strength of the joint is highly dependent on the applied material property for the 10.9 bolt. A piecewise linear stress-strain relationship is applied. Experimentally obtained bolt material properties found in the literature $[3,4,12,15,16]$ have varying characteristics at yielding and varying ultimate strength $\left(f_{\mathrm{u}}=\right.$ $\left.910 \div 1160 \mathrm{kN} / \mathrm{mm}^{2}\right)$ and ultimate strain $\left(\varepsilon_{\mathrm{u}}=7 \div 14 \%\right)$. Shi et al. [12] applied a trilinear stress-strain relationship, while Fan et al. [3] and Coelho et al. [15] applied multilinear characteristics with a more refined stress-strain characteristic around yielding. In this paper, the applied material model for the bolt is based on [3], with $\varepsilon_{u}=8 \%$ and assuming that failure occurs when the ultimate strain is reached. This multilinear model is detailed in Table 4.

Table 4 Material properties of the high strength bolt based on [3]

\begin{tabular}{lccccc}
\hline Strain $\varepsilon[\%]$ & 0 & 0.325 & 0.736 & 1.137 & 8 \\
\hline Stress $\sigma\left[\mathrm{N} / \mathrm{mm}^{2}\right]$ & 0 & 665 & 800 & 905 & 925 \\
\hline
\end{tabular}

\section{Parametric analysis of the joint A40 and B40}

In this section, the moment-rotation characteristics for System A and System B for the smallest T cross-section sizes (A40 and B40) are presented in detail. First, the results of the solid finite element model is studied. Afterwards, in sections 4.2-4.6, the influence of pretension, end-element size, bolt diameter, shear and normal force are detailed for joints A40 and B40. In section 5, results are presented for all section sizes (Table 1), which are designed for structures with $40 \div 80 \mathrm{~m}$ span (Table 2).

\subsection{Joint characteristics}

The goal of the joint analysis is to determine the behaviour of the joint for both in-plane $\left(M_{\mathrm{z}}\right)$ and out-of-plane $\left(M_{\mathrm{y}}\right)$ bending moments. The obtained moment-rotation results will be used for spring characteristics in the design of roof structures, as it is detailed in section 5 .

Because the applied cross-section is mono-symmetric, the $M_{\mathrm{y}}$ moment-rotation behaviour is different for positive and negative load values (notation according to Fig. 5), so these characteristics has to be determined separately. The results show that for A40, under a negative load, the stiffness and ultimate load of the joint is similar to that under a positive load, while it is $40 \%$ higher for B40 (Fig. 9). The reason for this is that in A40, the bolts are placed equidistant from the middle of the node and the end-element and the flange have similar heights. However, B40 has an asymmetric bolt arrangement, the neutral axis is below the axis of the node, and a larger area of contact surface can be activated when the load is negative. In the following calculations, if not indicated otherwise, the $M_{\mathrm{y}}$ results based on positive force are presented.

As for determining the in-plane bending behaviour, introducing the point load in different heights of the T section might affect the results. To exclude the effect of rotation of the beam, the point load is introduced in the shear centre of the $\mathrm{T}$ section. The obtained moment rotation results are compared to results from a model when the load is introduced in the geometric centre, and it is concluded that the differences are very small.

The length of the test element is chosen long enough to minimize the effect of shear force on the moment-rotation behaviour, as it will be seen in section 4.5. The results presented in this section are all calculated by applying $P=50 \mathrm{kN}$ pretension on the bolts. It will be shown later, that pretension has a significant effect on the joint stiffness.

Table 5 summarizes the results obtained for both joint systems for the smallest T cross-section sizes. $M_{\mathrm{u}}$ is the ultimate bending moment in the joint. The initial stiffness $\left(k_{\text {ini }}\right)$ is calculated from the moments $M_{\text {lin,y }}$ and $M_{\text {lin,z }}$ corresponding to $0.2 \%$ rad rotation. The presented rotations are calculated by excluding the effect of the elastic deformation of the beam. The elastic deformation accounts for around $30 \%$ of the total deformations in the elastic range for the model with $780 \mathrm{~mm}$ length.

From Table 5 and Fig. 9 and 10 it can be concluded, that A40 is stiffer in $M_{\mathrm{y}}$ direction, because the bolt distance is larger; while B40 is stiffer in $M_{\mathrm{z}}$ direction, because the end-element is larger. Several parameters may influence the moment-rotation characteristics of the joint. In sections 4.2-4.6, the influence of pretension, end-element size, bolt diameter, shear and normal force are detailed for the smallest cross-section sizes A40 and B40. In section 5, results are presented for all the section sizes, which are designed for structures with $40 \div 80 \mathrm{~m}$ span (Table 1 ).

In this study, the translational stiffness values are all assumed to be fully rigid. Hwang investigated the effect of bolt clearance on several splice joints [5]. The joint systems investigated in this paper are end-face joints, which is much stiffer in axial direction than splice joints [5]. The initial axial stiffness of B40 is $520 \mathrm{kN} / \mathrm{mm}$. Therefore, assuming that the threaded bolt is 

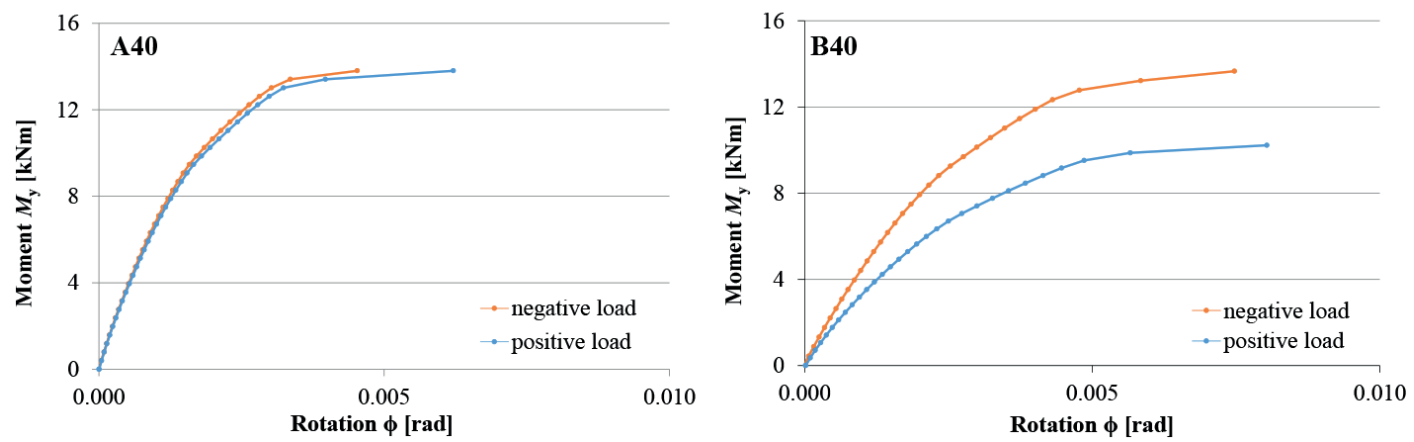

Fig. 9 Moment-rotation curves under positive and negative $M_{\mathrm{y}}$ load for joint A40 and B40
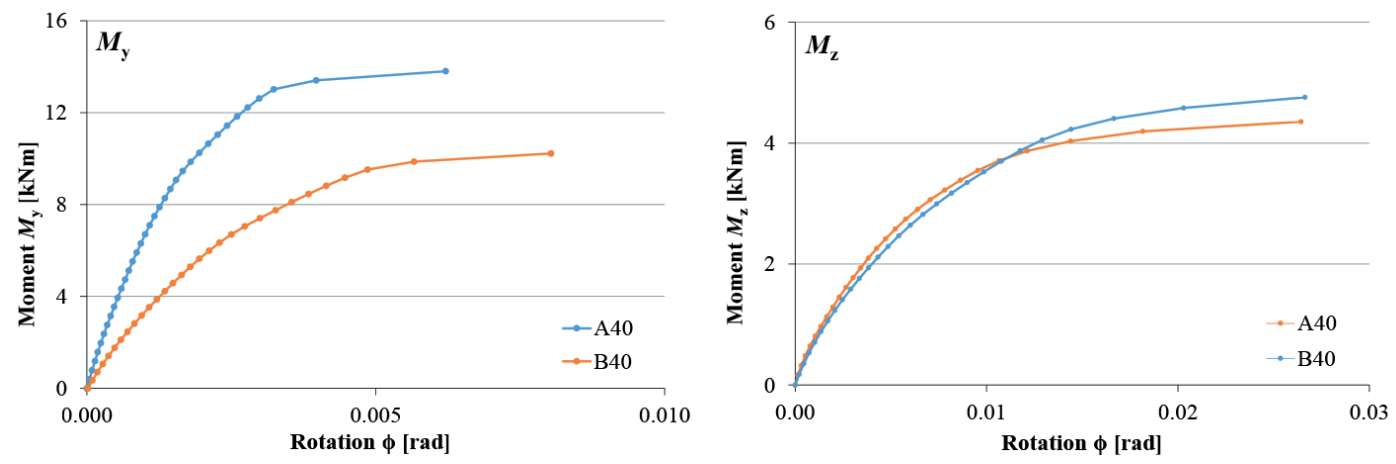

Fig. 10 Comparison of the moment-rotation curves of joint A40 and B40
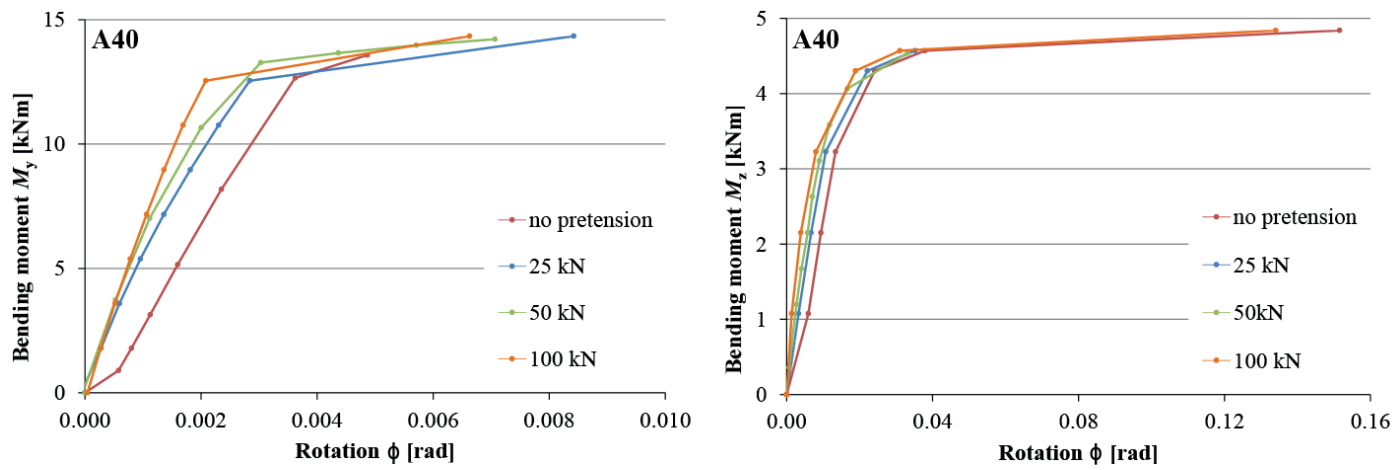

Fig. 11 Effect of pretension on the bending behaviour for A40

tight enough, the axial stiffness of the joint can be considered fully rigid for this joint type.

Investigating the joint loaded with a rotational moment $M_{\mathrm{x}}$, it can be concluded, that the torsional rigidity of the joint is significantly higher than that of the beam element. Thus, the torsional stiffness of the joint can also be considered fully rigid.

Table 5 Initial stiffness and maximum bending moment of the joints

\begin{tabular}{lcccccc}
\hline & \multicolumn{3}{c}{$\mathrm{A} 40$} & $\mathrm{~B} 40$ \\
& $\mathrm{Y}+$ & $\mathrm{Y}-$ & $\mathrm{Z}$ & $\mathrm{Y}+$ & $\mathrm{Y}-$ & $\mathrm{Z}$ \\
\hline$k_{\text {ini }}[\mathrm{kNm} / \mathrm{rad}]$ & 5195 & 5334 & 652 & 2876 & 3964 & 601 \\
$M_{\mathrm{u}}[\mathrm{kNm}]$ & 13.8 & 13.8 & 4.4 & 10.2 & 13.7 & 4.8 \\
\hline
\end{tabular}

\subsection{Effect of pretension}

The effect of applying pretension on the bolts is analysed in this section. Both bolts are subjected to $P=25,50$ and 100 $\mathrm{kN}$ pretension force and moment-rotation results are compared to the joint with no pretension. As mentioned earlier, the bolt holes in the nodes are slightly bigger than the bolt diameter. This bolt looseness affects the initial bending stiffness for the joint without pretension, as can be seen in Fig. 11: a large slip occurs at the beginning of loading. By applying pretension on the bolts, the stiffness is constant until plasticity occurs in the joint. Pretension increases the initial bending stiffness around both axes significantly: $+58 \%$ for $M_{\mathrm{y}}$ and $+160 \%$ for $M_{\mathrm{z}}$, if $P=50 \mathrm{kN}$.

According to the Eurocodes [14], 70\% of the tensile resistance of the bolt shall be applied as a pretension force. Thus, in further parametric analysis, a pretension force of $P=50 \mathrm{kN}$ is used for M12 bolts and $P=100 \mathrm{kN}$ for M16 bolts.

\subsection{Effect of end-element size}

The $M_{\mathrm{z}}$ bending stiffness is relatively small compared to the $M_{\mathrm{y}}$ bending stiffness of the joint. By analysing the chosen roof structures, it can be shown, that a small increase of the in-plane bending stiffness significantly increases the ultimate load of the structure. Therefore, width $\left(g_{1}\right)$, length $\left(g_{2}\right)$ and height $\left(g_{3}\right)$ of 

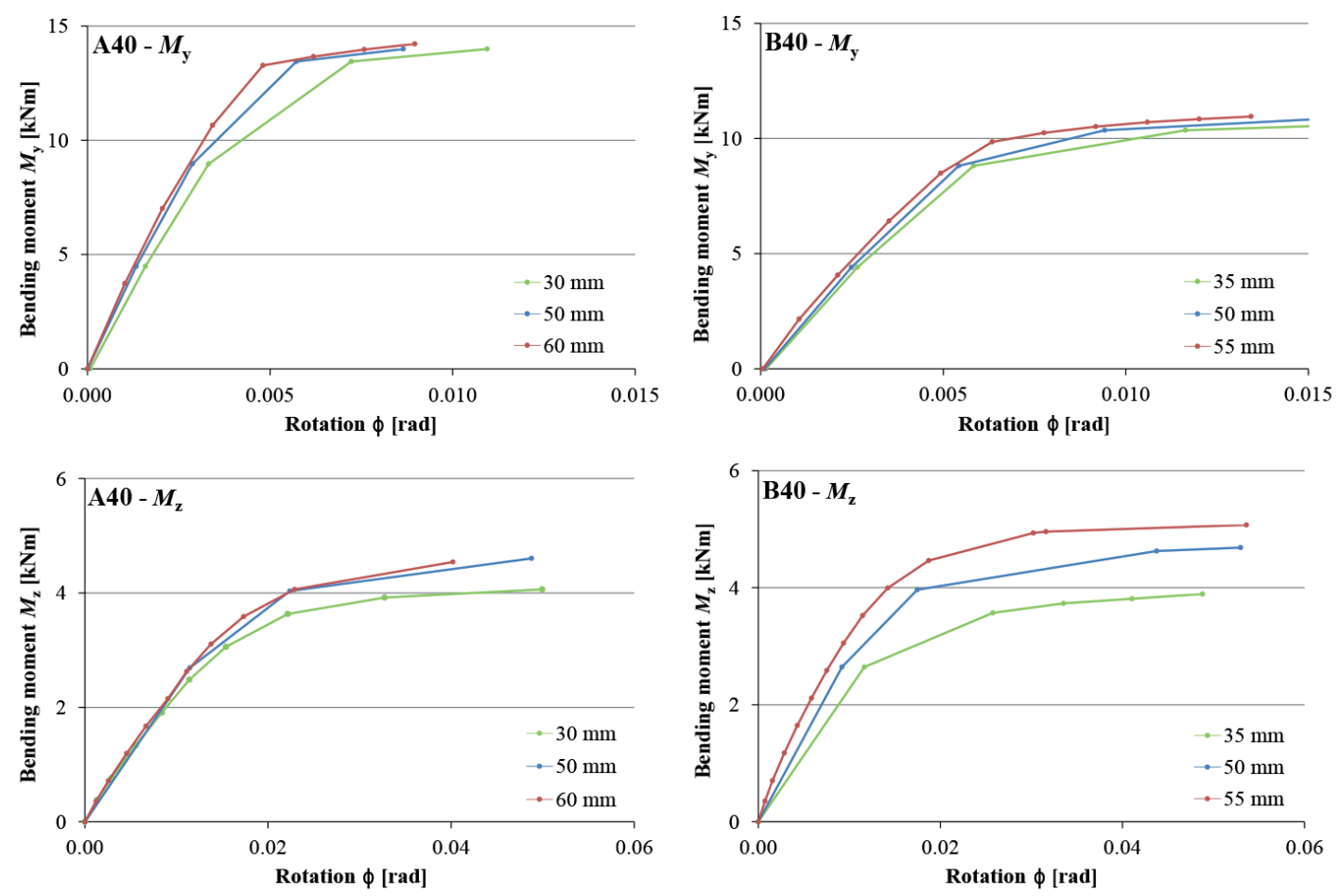

Fig. 12 Effect of end-element width $\left(g_{1}\right)$ on the bending behaviour for A40 and B40 $\left(g_{2}=40 \mathrm{~mm}, g_{3}=40 \mathrm{~mm}\right)$
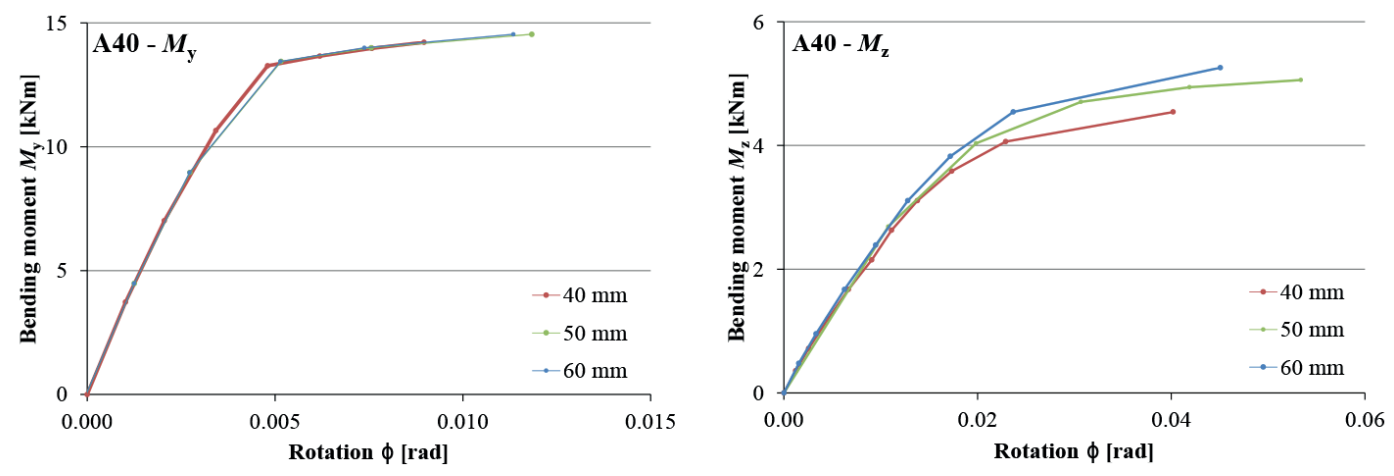

Fig. 13 Effect of end-element length $\left(g_{2}\right)$ on the bending behaviour for A40 $\left(g_{1}=60 \mathrm{~mm}, g_{3}=40 \mathrm{~mm}\right)$
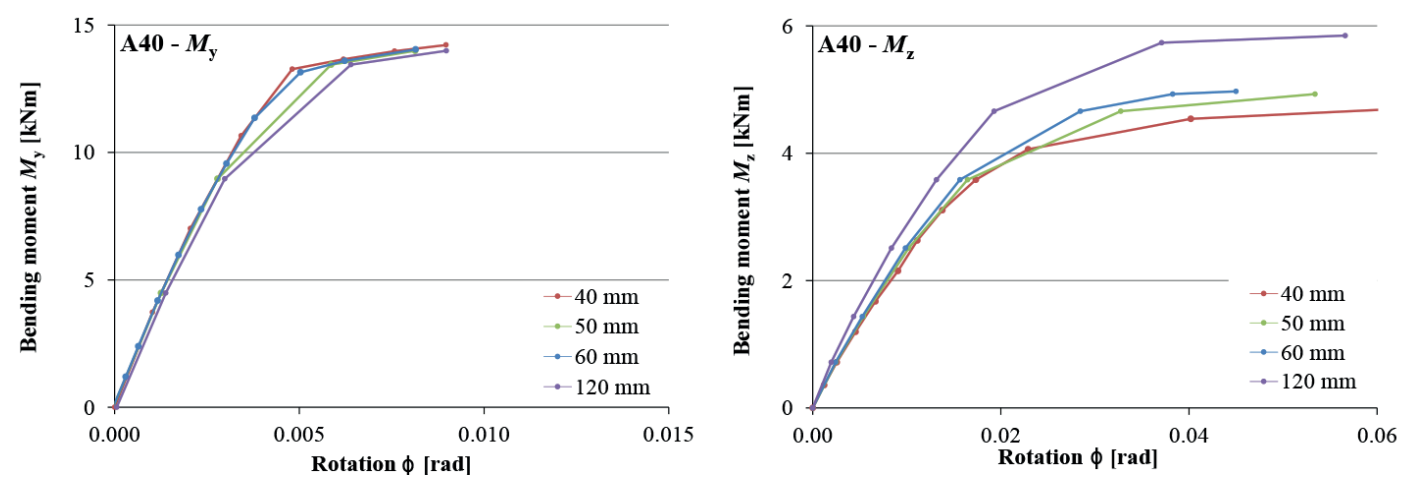

Fig. 14 Effect of end-element height $\left(g_{3}\right)$ on the bending behaviour for A40 $\left(g_{1}=60 \mathrm{~mm}, g_{2}=40 \mathrm{~mm}\right)$

the end-element sizes (Fig. 2-3) are analysed in this section, expected to increase the in-plane stiffness of the joint.

Fig. 12 shows the analysis results for joints with different end-element width. The maximum width depends on the geometry of the nodal element ( $g_{1}=60$ and $55 \mathrm{~mm}$ for A40 and B40). By increasing $g_{1}$, the in-plane moment capacity of A40 increases significantly (by 15\%). At the same time, unlike for joint B40, it has no effect on the in-plane stiffness, most probably, because the end-element height is too low for the joint A40. The moment capacity of B40 also increases significantly (by $30 \%$ ).

Choosing the right length of the end-element is very important to ensure enough in-plane stiffness. This could be important to prevent both flexural buckling about the weaker axis and lateral torsional buckling. Analysing this question is beyond the 
scope of this paper. Fig. 13 shows the bending-rotation curves for A40 joints with different end-element length values. Obviously, the out-of-plane bending behaviour is not influenced, but the in-plane moment capacity significantly increases with only a small increase in the length of the end-element (increased $15 \%$ from $g_{2}=40 \mathrm{~mm}$ to $g_{2}=60 \mathrm{~mm}$ ).

Fig. 14 shows the bending-rotation curves for A40 with different end-element heights. Increasing the height of the end-element from $g_{3}=40$ to 60 and to $120 \mathrm{~mm}$ increases the stiffness from $k_{\text {ini,z }}=471$ to 514 and to $688 \mathrm{kNm} / \mathrm{rad}$, while the strength increases from $M_{\mathrm{u}, \mathrm{z}}=4.8$ to 5.2 and to $5.9 \mathrm{kNm}$. This means that the end-element needs to be larger to have a significant effect on the stiffness, which might not be economic.

It can be concluded, that in order to increase the in-plane bending stiffness of the joints for B40, it is enough to increase the end-element width, but for A40 both the height and width needs to be increased.

\subsection{Effect of bolt diameter}

The effect of the bolt diameter on the moment-rotation characteristics is analysed. Two bolt diameters are compared (M12 and M16) with a pretension of 50 and $100 \mathrm{kN}$ respectively, while the sizes of the components are kept constant. Increasing the bolt diameter increases the bending capacity (by $50 \%$ for the case on Fig. 15) of the joints. For the larger bolt, the pretension force is higher, which increases the stiffness of the joints as well, as already discussed in section 4.2.

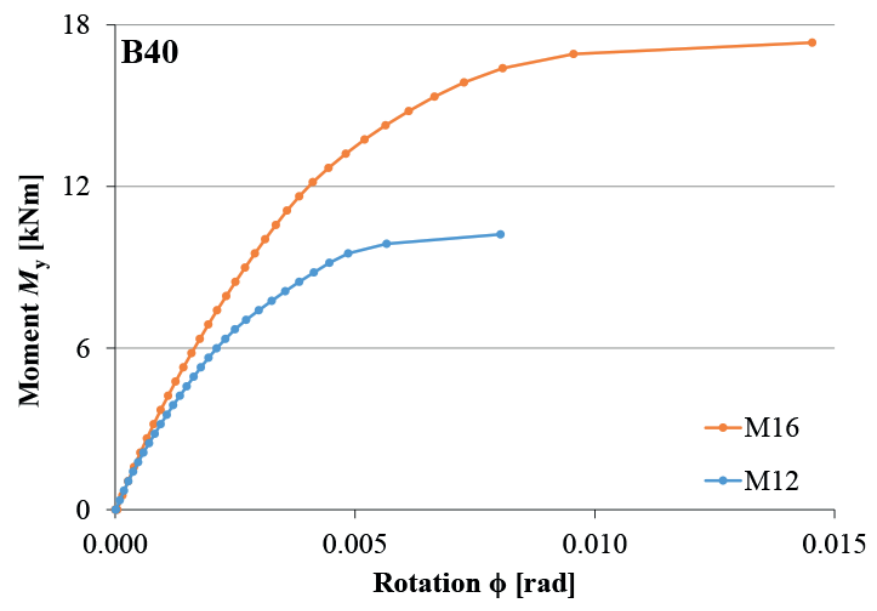

Fig. 15 Effect of bolt diameter on the bending behaviour of joint B40

\subsection{Effect of shear force}

The previously detailed parametric analysis is performed for beams, where the moment is introduced by loading the cantilever with a point load at the free end (Fig 5). This also introduces a shear force in the joint that may have a negative effect on the moment-rotation curve. Thus the cantilever has to be long enough to minimize the effect of the shear force. To demonstrate the effect of shear, a beam with pure bending $\left(+M_{\mathrm{y}}\right)$ is compared to beams of different lengths $(L=150 \div 780 \mathrm{~mm})$ with a point load on the end.
Results are summarized in Fig. 16. If the length of the beam is larger than half a meter, the effect of shear force is negligible. For very short elements though, the shear force may be higher than the friction force between the end-element and the node. Due to the bolt clearance, the beam slips and therefore the moment-rotation stiffness and strength is lower than for a longer beam. The presented moment-rotation results in the rest of the paper is with beam length $L=780 \mathrm{~mm}$.

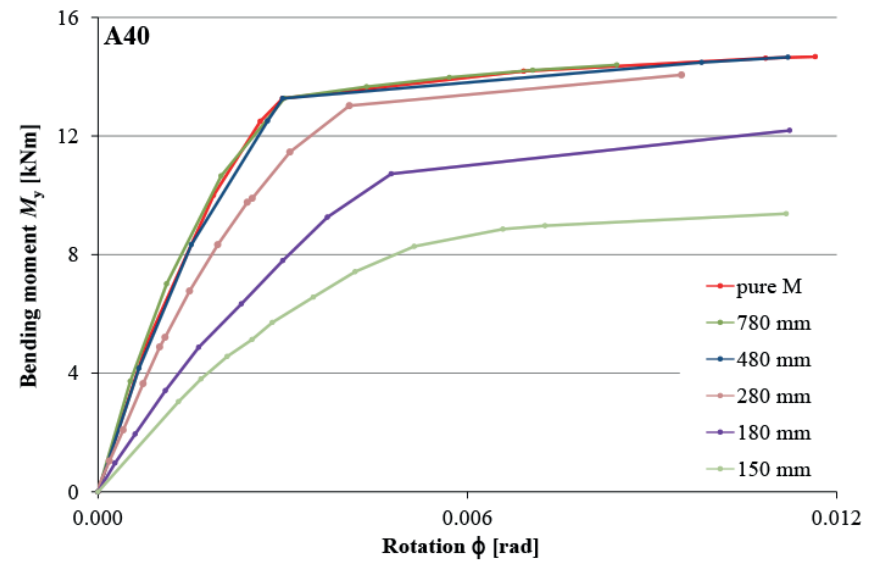

Fig. 16 Effect of shear force on the moment-rotation curve for cantilevers with different length for joint A40

\subsection{Effect of normal force}

Until now, only the bending capacity of the joint is analysed. However, in a grid shell structure, normal forces in the joints are significant, dependent on the loading and the curvature of the structure. Therefore, in this section the effect of normal force $(N)$ on the bending stiffness is analysed. A normal force is simultaneously applied in the geometric centre of the T crosssection. Instead of applying a constant normal force, $N$ is proportionally increased with the bending force, while it reflects the actual loading conditions better [3].

The ratio of normal force to bending moment for a structure is dependent on the angle and the length of the adjacent beams and the direction of the loading. Results can be seen in Fig. 17 for a structure with only two beams, where the force is perpendicular to the shell surface. The moment in the joints is calculated based on the moment caused by $F$ (Eq. (1)) plus the moment increment caused by the normal force.

In the presence of compression force, bending in a joint is initially transferred to the nodal element through the surfaces in contact, and thus the bolts will work only in a later phase of the loading. This increases both the bending stiffness and the bending capacity of the joint. If the compression is too high $(N / M>6)$, the bending capacity of the joint becomes lower (Fig. 18). The reason for this is that the part of the beam web that is welded to the end-element becomes plastic before the bolt. The increase of stiffness is higher for B40, than for A40, as it has larger contact surfaces between the end-element and the nodal element. 

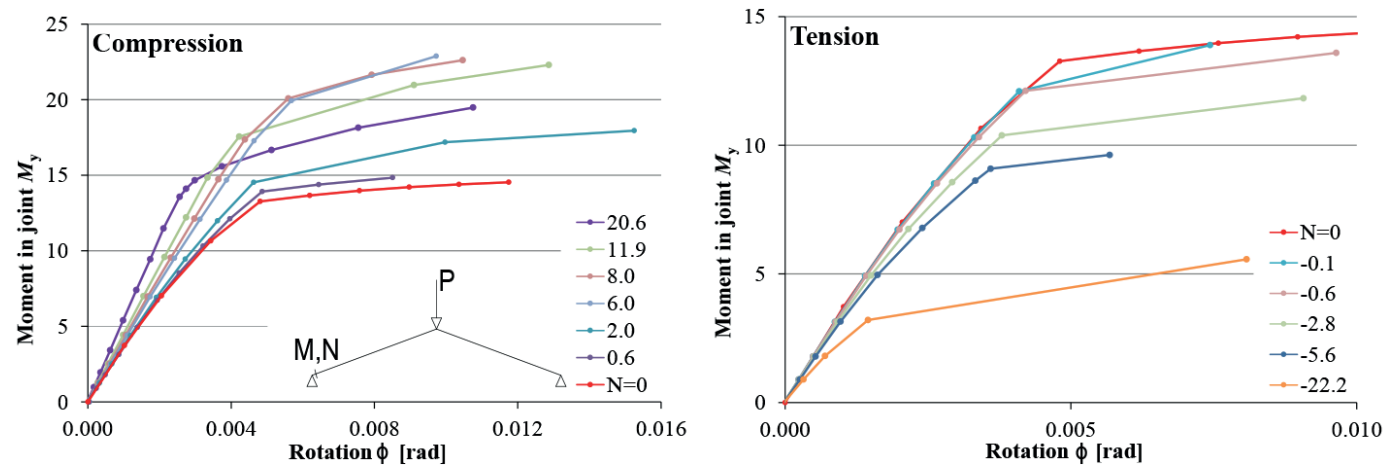

Fig. 17 Bending behaviour $M_{\mathrm{y}}$ for A40 for different $N / M$ ratios; compression (left) and tension (right)
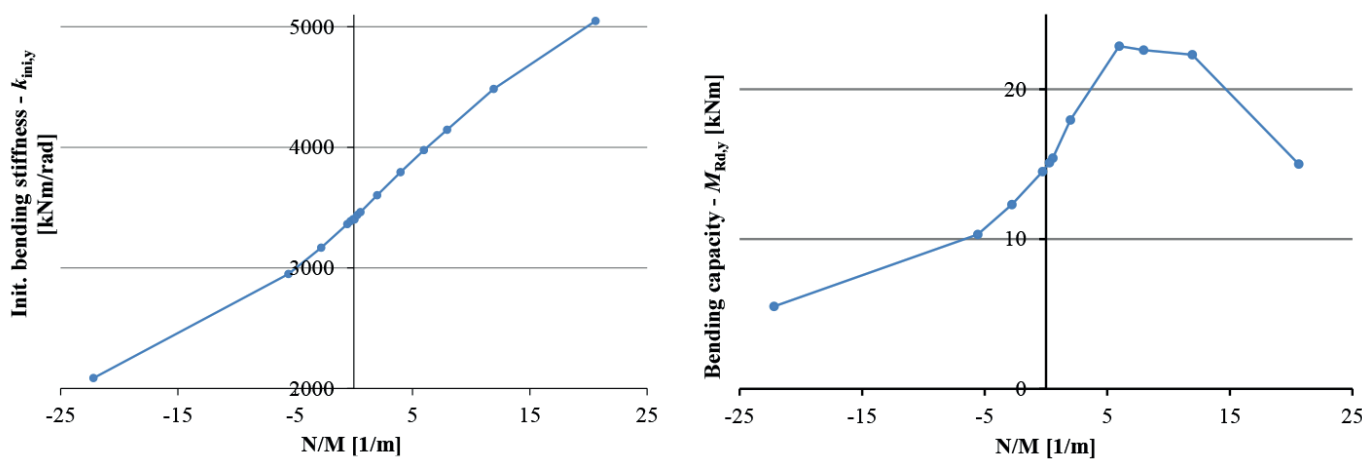

Fig. 18 Effect of normal force on the initial stiffness (left) and bending capacity (right) - A40

Table 6 Effect of various parameters on the moment-rotation characteristics of joints

\begin{tabular}{|c|c|c|c|c|c|c|c|c|c|}
\hline \multirow{2}{*}{\multicolumn{2}{|c|}{ Parameters }} & \multicolumn{4}{|c|}{ A40 } & \multicolumn{4}{|c|}{40} \\
\hline & & $k_{\text {ini,y }}$ & $M_{\mathrm{u}, \mathrm{y}}$ & $k_{\text {ini,z }}$ & $M_{\mathrm{u}, \mathrm{z}}$ & $k_{\text {ini,y }}$ & $M_{\mathrm{u}, \mathrm{y}}$ & $k_{\text {ini,z }}$ & $M_{\mathrm{u}, \mathrm{z}}$ \\
\hline Pretension & $P$ & ++ & & ++ & & ++ & & ++ & \\
\hline \multirow{3}{*}{$\begin{array}{l}\text { End-element } \\
\text { size }\end{array}$} & width $g_{1}$ & + & + & & + & + & + & ++ & ++ \\
\hline & length $g_{2}$ & & & & + & & & & \\
\hline & height $g_{3}$ & & & + & ++ & & & & \\
\hline Bolt diameter & $d$ & & ++ & & ++ & & ++ & & ++ \\
\hline Normal force & $N$ & ++ & ++ & & & ++ & ++ & + & \\
\hline
\end{tabular}

Further analysis showed that the normal force does not have any effect on the behaviour for joint A40, and only a small effect on the stiffness of joint B40.

\subsection{Summary of the results}

In the previous sections 4.2-4.6, the most important factors influencing the stiffness behaviour and strength of the developed joint were thoroughly investigated. The results for System A (joint A40) and System B (joint B40) are summarized in Table 6, indicating which parameters have the highest influence on the moment-rotation characteristic of a joint. The applied T cross-section is mono-symmetric and thus the out-ofplane inertia is significantly higher. Therefore, the most important parameter of the joints is the in-plane stiffness, which will also be shown in the next section through the analysis of the chosen roof structures.

The parametric analyses showed, that the in-plane stiffness of the joint is dependent on the end-element width for System B. On the other hand, the end-element needs to be taller and wider for System A to increase the in-plane stiffness. The $k_{\text {ini,z }}$ stiffness may also be increased by applying bolts with larger diameter for which the allowable pretension force is higher.

\section{Analysis of roof structures}

In the previous sections, the developed joint System A and B designed for a structure with $40 \mathrm{~m}$ span were discussed in detail. When analysing the chosen roof structures for larger spans, it was concluded, that the critical factor is the in-plane bendingstiffness. The parametric analysis revealed, that in case of System B, increasing the end-element width $\left(g_{1}\right)$ increases most significantly the stiffness for $M_{\mathrm{z}}$. Thus, joints developed for the $60 \div 80 \mathrm{~m}$ span roof structures have width as large as possible with the applied nodal element. For System A, increasing the end-element height would have the highest effect on $k_{\text {ini,z }}$, but only if the height is significantly increased. Therefore, also for this case, only the width is increased. On the other hand, pretension increases the stiffness, therefore both M12 and M16 bolts are applied. 
Table 7 Geometric details of the analysed joints

\begin{tabular}{|c|c|c|c|c|c|c|c|c|c|c|c|c|c|c|c|c|c|}
\hline \multicolumn{2}{|c|}{ Name of joint } & \multicolumn{16}{|c|}{$[\mathrm{mm}]$} \\
\hline A 40 & M12 & 50 & 70 & 103 & 63 & 12 & 22 & 8 & 45 & 23 & 24 & 6 & 100 & 25 & 60 & 40 & 40 \\
\hline A60 & M12 & 65 & 85 & 115 & 75 & 12 & 22 & 8 & 45 & 23 & 24 & 6 & 120 & 45 & 80 & 40 & 40 \\
\hline A 60 & M16 & 65 & 85 & 115 & 75 & 12 & 27 & 8 & 50 & 28 & 30 & 6 & 120 & 45 & 80 & 40 & 40 \\
\hline A80 & M16 & 80 & 105 & 132 & 92 & 12 & 27 & 8 & 50 & 28 & 30 & 6 & 140 & 65 & 100 & 40 & 40 \\
\hline B40 & M12 & 60 & 80 & 115 & 75 & 12 & 22 & 8 & 45 & 23 & 24 & 6 & 55 & 35 & 55 & 40 & - \\
\hline B60 & M12 & 80 & 100 & 135 & 95 & 12 & 22 & 8 & 45 & 23 & 24 & 6 & 85 & 65 & 60 & 40 & - \\
\hline B60 & M16 & 80 & 100 & 135 & 95 & 12 & 27 & 8 & 50 & 28 & 30 & 6 & 85 & 65 & 60 & 40 & - \\
\hline B80 & M16 & 90 & 10 & 145 & 105 & 12 & 27 & 8 & 50 & 28 & 30 & 6 & 105 & 85 & 65 & 40 & - \\
\hline
\end{tabular}

Table 8 Summary of joint stiffness and strength characteristics for developed $\mathrm{T}$ cross-sections for various spans

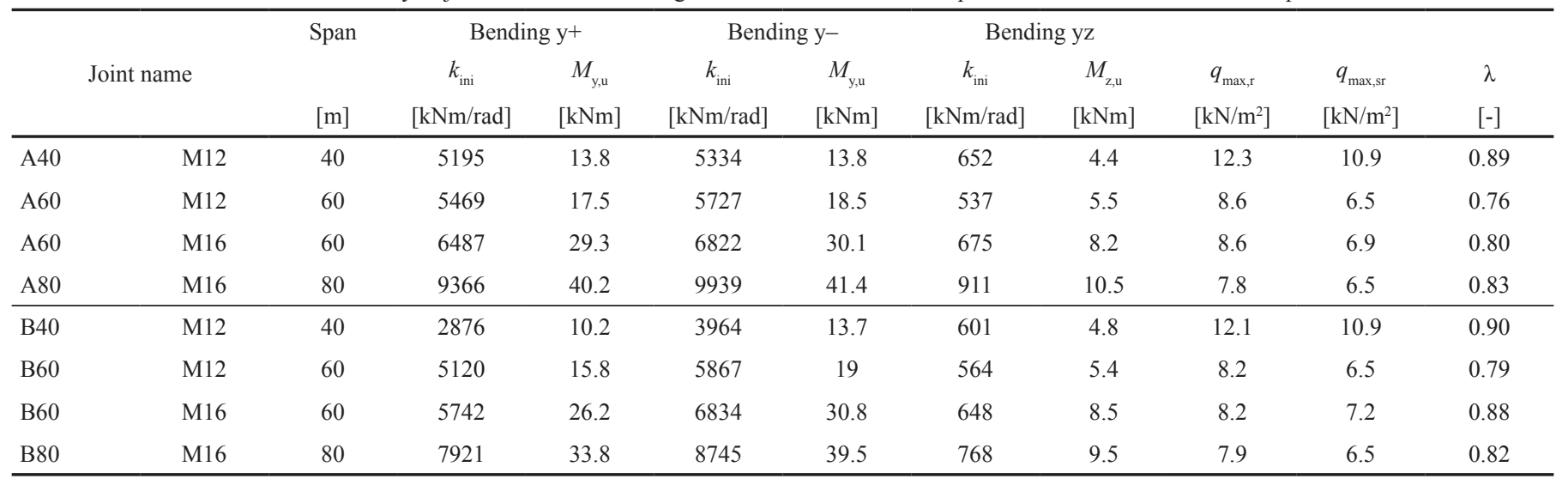

Table 7 and 8 summarizes the geometric parameters and the final results for the developed joints for $40 \div 80 \mathrm{~m}$-span structures. The moment-rotation characteristics of the joints presented in this table all have a beam length of $780 \mathrm{~mm}$ and for simplicity, the effect of axial force is neglected.

To prove that the developed joints are effective, the ultimate load of the roof structures (Fig. 1, Table 2) are calculated, both with rigid and with the developed bolted joints. The ultimate load of the roof structures under uniform distributed load are determined by geometrically and materially nonlinear analysis as discussed earlier in section 2. Each beam is modelled as 4 pieces of 6 degree-of-freedom beam finite elements with cubic shape functions (BEAM189 [2]). The nodal element is modelled as a short rigid element. The joints are modelled by nonlinear springs, which connect the beam elements to the nodal rigid elements [7]. The rotational multilinear spring characteristics are defined based on the results of the solid finite element models. Only the bending characteristics of the joints are nonlinear, the rest of the degrees of freedom are coupled.

The obtained ultimate load and moment-rotation characteristics for the rigid and semi-rigid structures are summarized in Table 8 and on Fig. 19. As an example, force-displacement curves of 60-m-span structures can be seen on Fig. 20. To evaluate the effectiveness of the joints, the ratio $\lambda$ is determined.

For the roof structures with $60 \div 80$-m-span, joints with M12 bolts are not sufficient, thus M16 bolts are required. Using a thicker bolt also allows a larger pretension force which enhances the bending stiffness. For $60 \mathrm{~m}$-span, the stiffness results are also included in Table 8 for the joints with M12 bolts, but they are not recommended to be used, as $\lambda$ is lower than 0.8 .

The deflection shape at $q_{\text {max,sr }}$ can be seen in Fig. 21 for B40, which reflects the failure mode of the structure. This deflection shape characterizes all the roof structures, whether they are rigid or semi-rigid. This failure mode is global, which means, that for several nodes of the structure a large deflection can be observed. The four areas close to the corners exhibit shelllike buckling, while the middle of the structure deflects significantly as well. Additionally to shell-like buckling, in a few semi-rigid structures, at $q_{\text {max,sr }}$, flexural buckling can also be observed. For the semi-rigid structure with the joint A60 M16, at $q_{\text {max,sr }}$, beams close to the corner buckle about the weak axis (see Fig. effig:21, where the beam with the largest deflection is marked). For A40, in-plane flexural buckling can be observed for both rigid and semi-rigid structures, for a large number of the beams. This means, that the $I_{\mathrm{z}}$ inertia of the cross-section is not sufficiently high. Flexural deflection of beams for System $\mathrm{B}$ is smaller.

Based on the obtained stiffness results, it can be concluded, that System A has a significantly higher positive out-of-plane bending stiffness compared to System B. The reason for this is obvious, as for System A, the bolt distance is larger than for System B. The in-plane bending stiffness of System A is higher for span $60 \div 80 \mathrm{~m}$. 

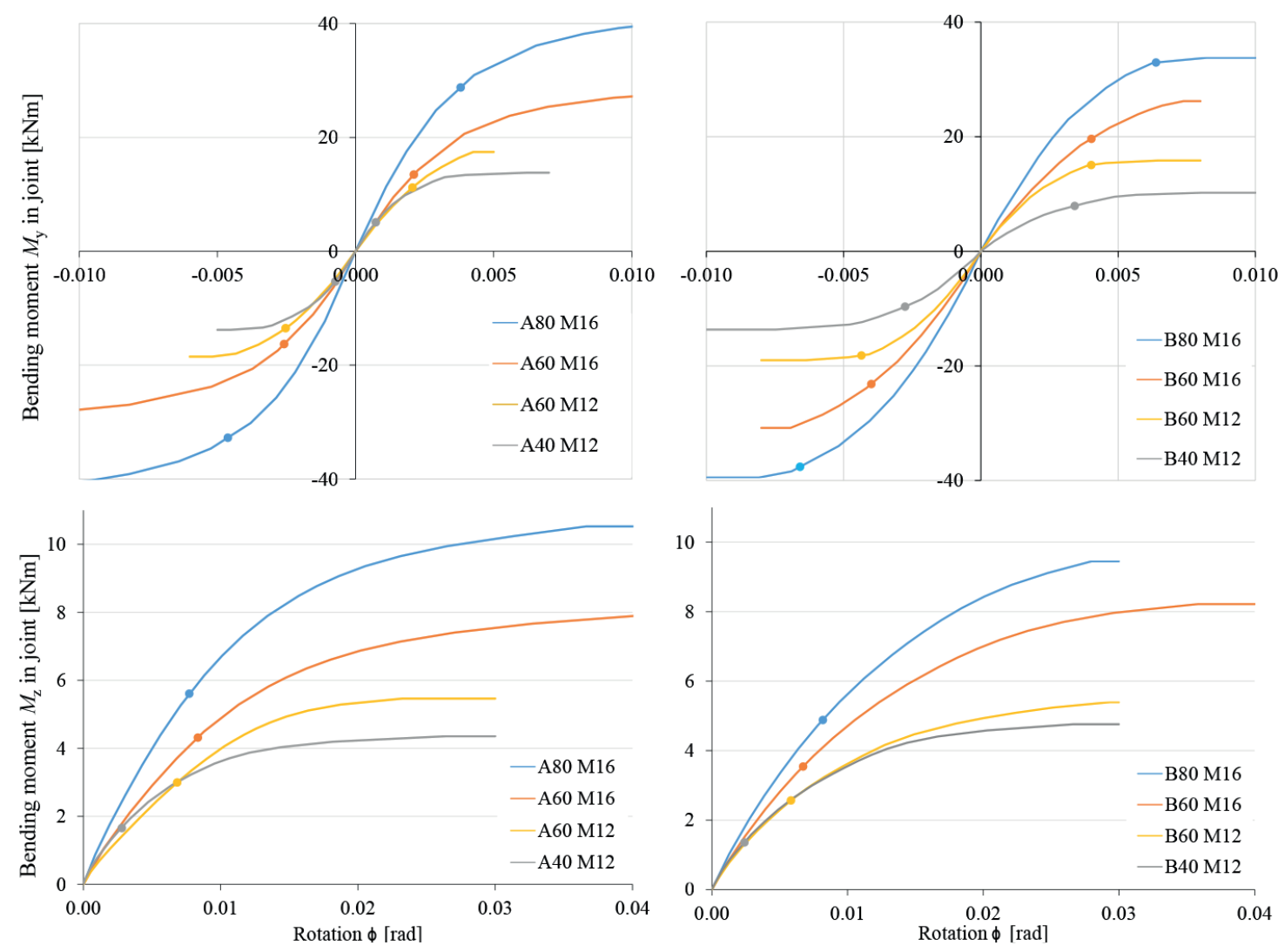

Fig. 19 Moment rotation characteristics of the developed joints, dots representing the maximal moments for the analysed shell structures at failure

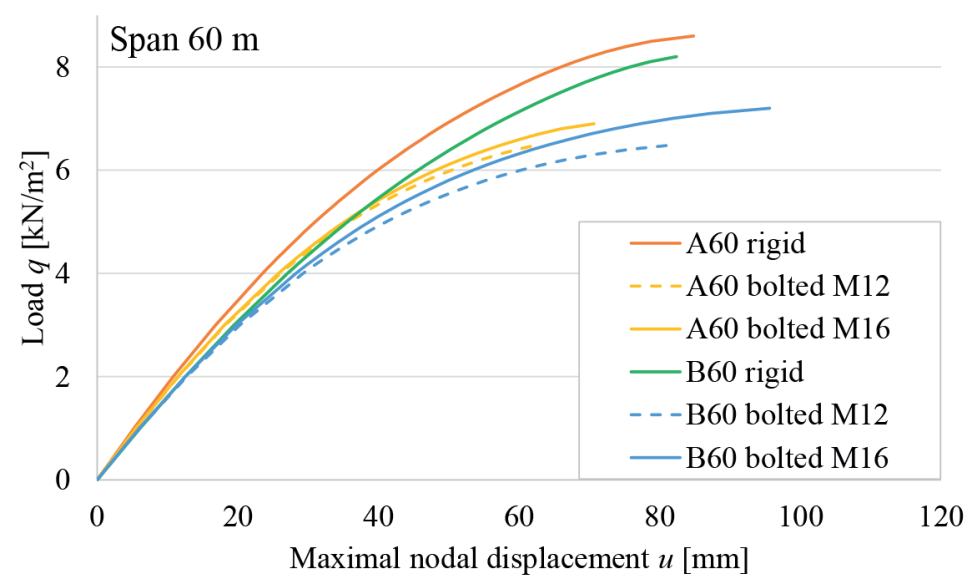

Fig. 20 Force-displacement diagrams of the nodes with largest displacement at $q_{\max }$, for 60 -m-span structures with bolted and rigid joints

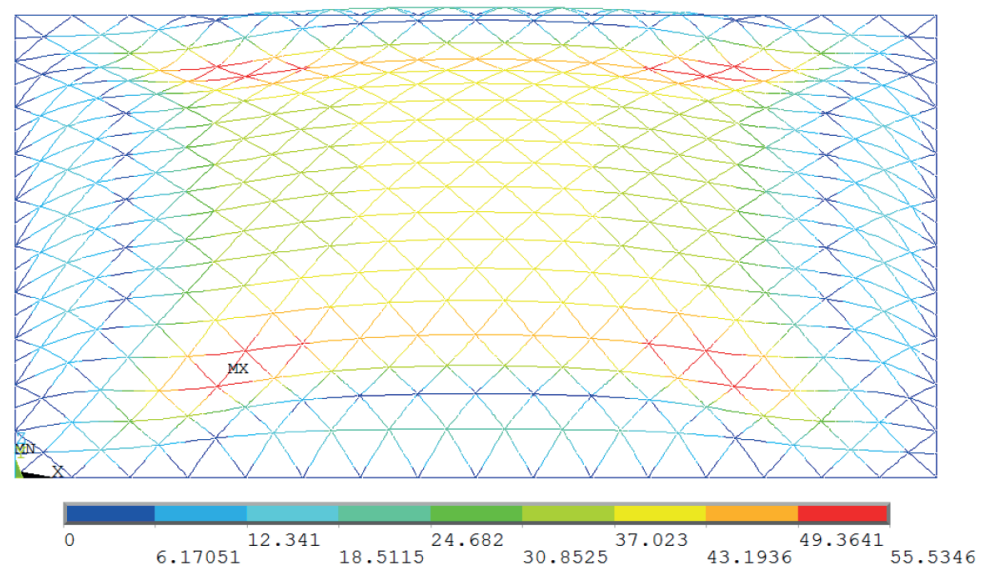

Fig. 21 Deflected shape at $q_{\text {max,sr }}$ of the structure with bolted joint B40, displacements are enlarged by 20 [mm] 


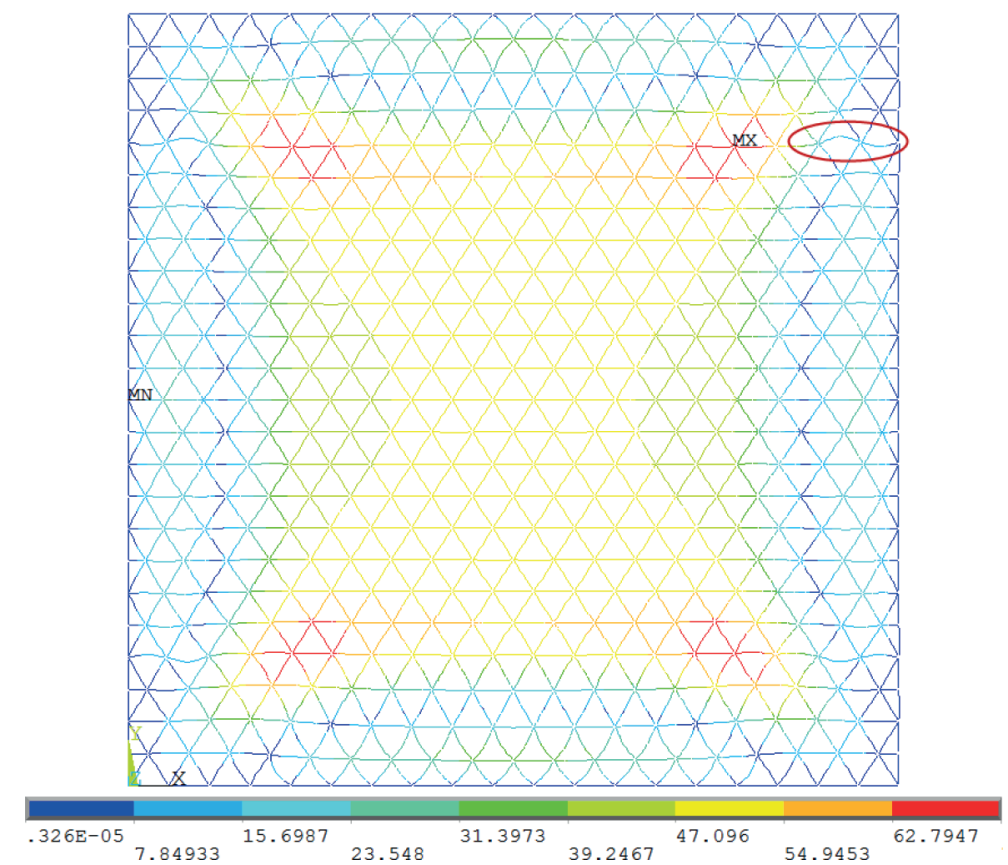

Fig. 22 Deflected shape at $q_{\text {max,sr }}$ of the structure with bolted joint A60 M16, displacements are enlarged by 30 [mm]

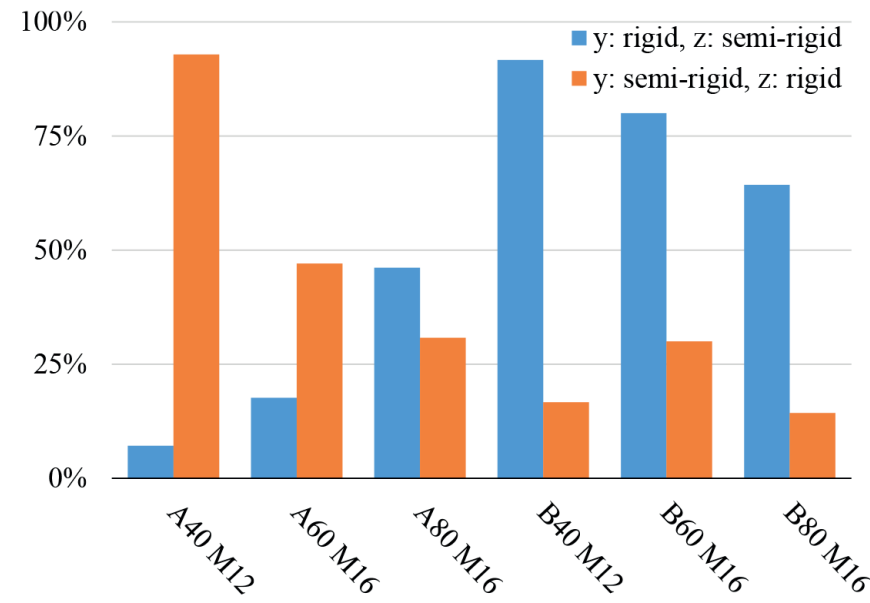

Fig. 23 Ultimate loads of structures with different bending stiffness components: $q_{\text {max, r-sr }}$ and ${ }_{\text {max,sr-r }}$ if $q_{\text {max,r }}$ is $100 \%$ and $q_{\text {max,sr }}$ is $0 \%$

The bending strength of System A and B are similar. As an exception, the positive out-of-plane bending strength is higher for System A, than for System B.

The ultimate load are also calculated for the structures with the following joints: semi-rigid out-of-plane and rigid in-plane $\left(q_{\text {max,s-s-r }}\right)$ components; and rigid out-of-plane and semi-rigid inplane $\left(q_{\text {max, }- \text { ss }}\right)$ components. The results are summarized in Fig. 23 ; in each case taking $q_{\text {max,sr }}$ as $0 \%$ and $q_{\text {max,r }}$ as $100 \%$. It can be seen, that the joints A40 and A60 can be strengthened by increasing its in-plane stiffness, while the rest of the joints can be strengthened by increasing its out-of-plane stiffness.

\section{Conclusions}

Two slightly different novel bolted joints were designed for $\mathrm{T}$ cross-sections applicable for free-form grid shell structures. System A has thick narrow flanges, while System B has thin flanges. The cross-section area for System A is slightly larger, while System B requires taller nodal and end-elements. The most important factors influencing the stiffness behaviour and strength of the developed joint system are summarized in Table 6. It was shown, that the most critical parameter of the joints is the in-plane stiffness, which is dependent on the end-element size and the bolt diameter and pretension. By finding an ideal end-element width and bolt diameter with appropriate pretension, joints were designed for roof structures with rectangular boundary spanning $40 \div 80$ meters. For medium span structures (40 m) M12 bolts, while for larger span structures $(60 \div 80 \mathrm{~m})$ M16 bolts are required. Both System A and B can be effectively used based on analysis of the chosen roof structures with the assumption, that the ultimate load of a semi-rigid structure is at least 0.8 times the ultimate load of a structure with rigid joints.

Furthermore, the following conclusions were made: (i) System A has a significantly higher positive out-of-plane bending stiffness compared to System B. (ii) The in-plane bending 
stiffness of System A is larger for span $60 \div 80 \mathrm{~m}$. (iii) The bending strength of System A and B are similar. As an exception, the positive out-of-plane bending strength is higher for System A, than for System B. (iv) The joints A40 and A60 can be strengthened by increasing its in-plane stiffness, while the rest of the joints can be strengthened by increasing its out-ofplane stiffness.

It was shown, that taking into account the effect of the normal force, the moment-rotation characteristics significantly changes. As a further study, this shall also be considered in the analysis of the roof structures.

\section{Acknowledgement}

The project presented in this article is partly supported by grants from the China Scholarship Council and the Natural Science Foundation of China under grant number 51308153 and 91315301.

\section{References}

[1] Stephan, S., Sanchez-Alvarez, J., Knebel, K. "Stabwerke auf freiformflächen”. Stahlbau, 73(8), pp. 562-572. 2004. https://doi.org/10.1002/ stab. 200490149

[2] Ma, H., Fan, F., Cao, Z., Cui, M., Shen, S. „Numerical simulation of semirigid joints in single-layer dome structures". Journal of the International Association for Shell and Spatial Structures, 52(1), pp. 3-18. 2011

[3] Fan, F., Ma, H., Chen, G., Shen, S. „Experimental study of semi-rigidjoint systems subjected to bending with and without axial force". Journal of Constructional Steel Research, 68(1), pp. 126-137. 2012. https://doi. org/10.1016/j.jcsr.2011.07.020

[4] Lopez, A., Puente, I., Serna, M. A. "Numerical model and experimental tests on single-layer latticed domes with semi-rigid joints". Computers \& Structures, 85(7-8), pp. 360-374. 2007. https://doi.org/10.1016/j.compstruc.2006.11.025

[5] Hwang, K-J., Knippers, J., Park, S-W. "Influence of various types node connectors on the buckling loads of grid shells". In: Proceedings of the Symposium of the International Association for Shell and Spatial Structures (IASS) Symposium 2009, Valencia, Spain, pp. 1841-1852.

[6] Kim, Y. J., Lee, Y. H., Kim, H. "Bending test of welded joints for single layer latticed domes". International Journal of Steel Structures, 8, pp. 357-367. 2008.

[7] Gidófalvy, K., Katula, L., Ma, H., Fan, F. "Semi-rigid free-form gridshells on rectangular plan". In: 7th European Conference on Steel and Composite Structures, Eurosteel 2014. Napoli: ECCS, 2014. pp. 971972. 2014

[8] Eurocode 3: Design of steel structures: part 1-1: General rules and rules for buildings. 1993-1-1:2005. 2005

[9] ANSYS version 14.5 User's Manual.

[10] Rhinoceros, version 5. www.rhino3d.com

[11] Grasshopper, version 0.9.0076. www.grasshopper3d.com

[12] Shi, G., Shi, Y., Wang, Y., Bradford, M. A. "Numerical simulation of steel pretensioned bolted end-plate connections of different types and details". Engineering Structures, 30(10), pp. 2677-2686, 2008. https:// doi.org/10.1016/j.engstruct.2008.02.013

[13] Hot rolled products of structural steels: part 2 :technical delivery conditions for non-alloy structural steels. 10025:2005," 2005.

[14] Eurocode 3: Design of steel structures: part 1-8 : Design of joints. 19931-8:2005," 2005
[15] A. M. G. aoCoelho, L. S. oes da Silva, and F. S. K. Bijlaard, "Finite element modeling of the nonlinear behavior of bolted-stub connections". Journal of Structural Engineering, 132(6), pp. 918-928. 2006. http:// dx.doi.org/10.1061/(ASCE)0733-9445(2006)132:6(918)

[16] Swanson, J. A., Kokan, D. S., Leon, R. T. "Advanced finited element modeling of bolted T-stub connection components". Journal of Constructional Steel Research, 5(5-8), pp. 1015-1031. 2002. https://doi. org/10.1016/S0143-974X(01)00098-0 